See Article page 1864 .

\title{
Commentary: Putting the lid on left main revascularization equipoise
}

Victor Dayan, MD, PhD, ${ }^{a}$ and Tom C. Nguyen, $\mathrm{MD}^{\mathrm{b}}$

Gaudino and Brophy ${ }^{1}$ should be congratulated on providing clarity into the role of percutaneous coronary intervention (PCI) versus coronary artery bypass grafting (CABG) surgery in patients with left main (LM) disease. The authors have performed a solid review into the evidence behind the best treatment for patients with LM disease. Their main message is that LM disease should be considered as part of coronary artery disease as a whole and not an independent entity. There are a paucity of data supporting long-term clinical equipoise between PCI and bypass surgery (CABG).

Equipoise considers uncertainty of the beneficial effect of one treatment versus the other. In the last 10 years, 5 clinical trials have been designed to address this dilemma using a noninferiority approach. In every case, the primary outcome for the noninferiority margin was assessed in the medium term (1-3 years) and not in the longer-term follow-up. Considering that patients included in these trials are young (mean age of 66 years old in EXCEL [Evaluation of XIENCE versus Coronary Artery Bypass Surgery for Effectiveness of Left Main Revascularization]), it would be desired for noninferiority to be tested in longer-term follow-up. If we consider noninferiority assessment in each of the LM trials, we find the following:

- Boudriot and colleagues-does not meet noninferiority after 1 year of follow-up. ${ }^{2}$

From ${ }^{\mathrm{a} C e n t r o}$ Cardiovascular Universitario, Universidad de la Republica, Montevideo, Uruguay; and ${ }^{\mathrm{b}}$ Department of Cardiothoracic and Vascular Surgery, University of Texas Health Science Center Houston, McGovern Medical School, Houston, Tex.

Disclosures: The authors reported no conflicts of interest.

The Journal policy requires editors and reviewers to disclose conflicts of interest and to decline handling or reviewing manuscripts for which they may have a conflict of interest. The editors and reviewers of this article have no conflicts of interest.

Received for publication Sept 11, 2020; revisions received Sept 11, 2020; accepted for publication Sept 11, 2020; available ahead of print Sept 18, 2020.

Address for reprints: Tom C. Nguyen, MD, University of Texas - Memorial Hermann, 6400 Fannin St, Suite 2850, Houston, TX 77004 (E-mail: tom.c.nguyen@gmail. com).

J Thorac Cardiovasc Surg 2022;163:1870-1

$0022-5223 / \$ 36.00$

Copyright (c) 2020 by The American Association for Thoracic Surgery

https://doi.org/10.1016/j.jtcvs.2020.09.054
Check for updates

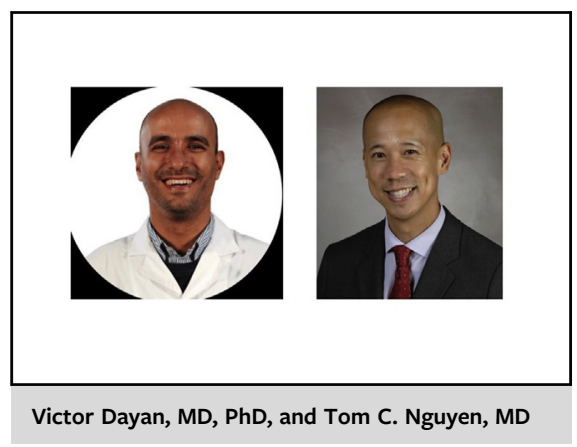

CENTRAL MESSAGE

There are a lack of data sup-

porting long-term equipoise be-

tween PCl and CABG in treating

patients with left main coronary

disease.

- SYNTAX (Synergy between Percutaneous Coronary Intervention with Taxus and Cardiac Surgery) trialdoes not meet noninferiority after 5 years of follow-up.

- PRECOMBAT (Premier of Randomized Comparison of Bypass Surgery versus Angioplasty Using SirolimusEluting Stent in Patients with Left Main Coronary Artery Disease) trial—does not meet noninferiority after 2, 5, and 10 years of follow-up (considering that it was underpowered). ${ }^{4}$

- EXCEL trial—does not meet noninferiority after 5 years of follow-up. ${ }^{5}$

- NOBLE (Nordic-Baltic-British left main revascularisation study) trial-PCI is inferior to CABG after 5 years of follow-up. ${ }^{6}$

Noninferiority trials are performed on the premise that to have an advantage for patients (in case of PCI, avoiding surgery) we may allow "certain" margin of worse outcome with the experimental treatment. This is the noninferiority margin that is set by the investigators of the trial. The authors mention an important aspect that needs to be highlighted. In contrast to EXCEL, NOBLE included in its primary outcome repeat revascularization (RR). It is established that RR is greater with PCI and, therefore, considering this, the authors of NOBLE established a margin wide enough to include this difference $(4 \%)$. The EXCEL trial did not include RR and, nonetheless, instead of placing a narrower margin for their primary outcome, the investigators placed margin of $4.2 \%$. If their margin should have 
been the same as NOBLE, the EXCEL trial would have been failed to show noninferiority. EXCEL also included mortality, stroke, myocardial infarction (MI), or RR as a secondary powered outcome. In this case, the noninferiority margin was set to $8.4 \%$, which is more than double the margin set in NOBLE for the same composite outcome (with the exception of including only spontaneous MI). Noninferiority trials are a great tool but may easily be manipulated to arrive to the intended outcomes.

Considering that no trial has demonstrated noninferiority of PCI and that pooled analysis from meta-analysis have shown greater risk for MI and RR, logic follows that equipoise is not met and therefore guidelines should reflect on it.

\section{References}

1. Gaudino M, Brophy JM. The controversy on the treatment of left main coronary artery disease. J Thorac Cardiovasc Surg. 2022;163:1864-9.
2. Boudriot E, Thiele H, Walther T, Liebetrau C, Boeckstegers P, Pohl T, et al. Randomized comparison of percutaneous coronary intervention with sirolimuseluting stents versus coronary artery bypass grafting in unprotected left main stem stenosis. J Am Coll Cardiol. 2011;57:538-45.

3. Morice M-C, Serruys PW, Kappetein AP, Feldman TE, Stahle E, Colombo A, et al. Five-year outcomes in patients with left main disease treated with either percutaneous coronary intervention or coronary artery bypass grafting in the synergy between percutaneous coronary intervention with taxus and cardiac surgery trial. Circulation. 2014;129:2388-94.

4. Park DW, Ahn JM, Park H, Yun SC, Kang DY, Lee PH, et al PRECOMBAT Investigators. Ten-year outcomes after drug-eluting stents versus coronary artery bypass grafting for left main coronary disease: extended follow-up of the PRECOMBAT trial. Circulation. 2020;141 1437-46.

5. Stone GW, Kappetein AP, Sabik JF, Pocock SJ, Morice M-C, Puskas J, et al. Fiveyear outcomes after PCI or CABG for left main coronary disease. $N$ Engl J Med. 2019;381:1820-30.

6. Holm NR, Mäkikallio T, Lindsay MM, Spence MS, Erglis A, Menown IBA, et al; NOBLE investigators. Percutaneous coronary angioplasty versus coronary artery bypass grafting in the treatment of unprotected left main stenosis: updated 5-year outcomes from the randomised, non-inferiority NOBLE trial. Lancet. 2020;395: $191-9$.
See Article page 1864 .

\section{Commentary: The fate of patients with left main coronary artery disease may be dictated by distorted science}

\section{Walter J. Gomes, MD, PhD}

Gaudino and Brophy ${ }^{1}$ impart a didactic approach examining the evidence on whether left main coronary artery disease may be considered a separate entity within the spectrum of coronary artery disease, and adds to the growing stir over the Evaluation of XIENCE versus Coronary Artery Bypass Surgery for Effectiveness of Left Main Revascularization (EXCEL) trial and the assertions

\footnotetext{
From the Cardiovascular Surgery Discipline, Escola Paulista de Medicina and São Paulo Hospital, Federal University of São Paulo, São Paulo, Brazil.

Disclosures: The author reported no conflicts of interest.

The Journal policy requires editors and reviewers to disclose conflicts of interest and to decline handling or reviewing manuscripts for which they may have a conflict of interest. The editors and reviewers of this article have no conflicts of interest.

Received for publication Sept 15, 2020; revisions received Sept 15, 2020; accepted for publication Sept 17, 2020; available ahead of print Sept 28, 2020.

Address for reprints: Walter J. Gomes, MD, PhD, Cardiovascular Surgery Discipline, Escola Paulista de Medicina and São Paulo Hospital, Federal University of São Paulo, Rua Botucatu 740, São Paulo, SP, 04023-900 Brazil (E-mail: wjgomes1012@gmail.com).

J Thorac Cardiovasc Surg 2022;163:1871-2

0022-5223/\$36.00

Copyright (c) 2020 by The American Association for Thoracic Surgery

https://doi.org/10.1016/j.jtcvs.2020.09.077
}

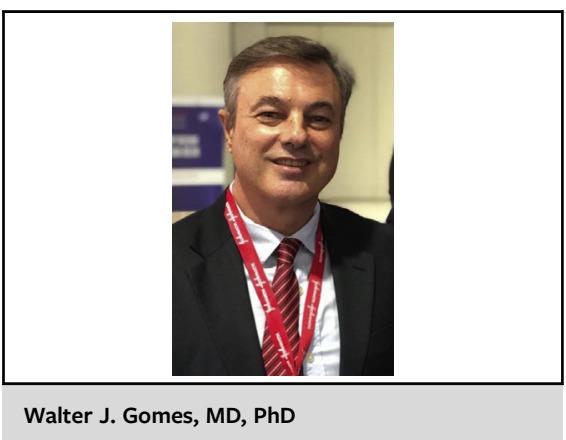

CENTRAL MESSAGE

The alleged flaws with the EXCEL

trial led to growing stir over

misconduct. Some deviations

from the original protocol may

have caused the conclusion to

be contradictory with clinical

findings.

of misconduct, analyzing every contradictory aspect related to the EXCEL trial.

The earlier claim from the EXCEL trial authors that they were unable to determine the per-protocol prespecified secondary end point of myocardial infarction (MI) rate according to the universal definition of MI (UDMI) because 